\title{
Francisco de Magariños: un americano tensionado entre la fidelidad a la monarquía y la construcción de una nueva república
}

\author{
MARTA BONAUDO \\ Unidad Ejecutora en Red Investigaciones Socio-Históricas Regionales del \\ Consejo Nacional de Investigaciones Científicas y Técnicas/ \\ Universidad Nacional de Rosario \\ mbonaudo@tower.com.ar
}

\begin{abstract}
Resumen
Este artículo pretende analizar e interpretar una coyuntura histórica a través de la biografía de un actor "secundario" de la trama, Francisco de Magariños, apelando a una mirada transatlántica del género. El interés por los procesos de configuración de nuevas formas de legitimidad política, surgidas al calor de los procesos revolucionarios que atravesaron tanto el mundo europeo como el americano, nos condujo a acercarnos en esta oportunidad a esa problemática desde el registro biográfico como un modo de recuperación de ciertas dimensiones a las que no era posible acceder con otras "herramientas". Consideramos que ella nos permite explorar más densamente las tramas de las culturas políticas de tales sociedades, alcanzando una mayor comprensión tanto de los conocimientos, como de los valores, las creencias, los sentimientos, las predisposiciones, las actitudes y las prácticas que los individuos ponen en juego ante el poder y los asuntos ligados a él.
\end{abstract}

Palabras clave: biografías transatlánticas; culturas políticas; diputación americana; Trienio Liberal.

\section{Francisco de Magariños: an American Torn between Loyalty to the Monarchy and the Construction of a New Republic}

\begin{abstract}
This article seeks to analyze or interpret a historical event though the biography of one of its "secondary" actors, Francisco de Magariños, and calls for a transatlantic approach to gender. The authors' interest in configuring new forms of political legitimacy, in the context of the revolutionary processes experienced by both the European and American world, led them to approach this issue from a biographical point of view, as a means of recovering certain dimensions that could not be accessed using other "tools". This arguably enables them to explore in greater detail the events of the political cultures of these societies, to foster greater understanding of the knowledge, values, beliefs, feelings, predispositions, attitudes and practices individuals express in response to power and associated issues.
\end{abstract}

Key words: transatlantic biographies; political cultures; American deputation; Liberal Triennial.

Fecha de recepción: Fecha de aceptación:

13 de enero de $2013 \quad 1$ de julio de 2013 


\title{
Francisco de Magariños: un americano tensionado entre la fidelidad a la monarquía y la construcción de una nueva república*
}

\author{
Marta Bonaudo
}

Como en las tragedias clásicas, en esta historia es el coro el que dice lo que el protagonista no puede o no sabe decir. Es el coro el que dice lo que está en juego...

ISABEL BuRDIEL. Isabel II. No se puede reinar inocentemente

INTERROGANTES Y PRESUPUESTOS PARA UN ESTUDIO

- Qué es lo que está en juego en este artículo? Indudablemente una mane6 ra de explorar e interpretar una coyuntura histórica a través de la biografía de uno de los actores "secundarios" de la trama, apelando a una mirada transatlántica del género. La propuesta, vinculada a un proyecto mayor, intenta dar cuenta de un campo más amplio de preocupaciones. Nuestro interés en los últimos años por los procesos de configuración de nuevas formas de legitimidad política, surgidas al calor de los procesos revolu-

\footnotetext{
* Este trabajo es tributario del proyecto del que formo parte: "Los artífices de la representación parlamentaria. Desarrollos biográficos entre España y América" dirigido por la doctora María Sierra e integrado también por los doctores María Antonia Peña Guerrero y Rafael Zurita Aldeguer.
}

cionarios que atravesaron tanto el mundo europeo como el americano, nos condujo a acercarnos a esa problemática desde diferentes ángulos. Uno de ellos es, sin dudas, el que apela al registro biográfico como un modo de recuperación de ciertas dimensiones a las que no es posible acceder con otras "herramientas". El objetivo de elucidar cómo se viabilizó la construcción de comunidades políticas imbuidas de las lógicas liberales y republicanas nos generó, a su vez, múltiples interrogantes sobre la o las culturas políticas de tales sociedades, orientando nuestra búsqueda de respuestas hacia los conocimientos, los valores, las creencias, los sentimientos, las predisposiciones, las actitudes y las prácticas de los individuos ante el poder y los asuntos ligados a él. Por eso consideramos pertinente indagar esas dimensiones a través de la biografía. Partíamos del presupuesto de que la misma constituía un laboratorio privilegiado para proceder al análisis atendiendo a diversos registros. Por una parte, ella podía brindarnos -desde la mirada y las percepciones de los propios actores- información sobre fenómenos como el de ese trasiego de ideas y sensibilidades políticas que recorrieron a lo largo del siglo XIX los espacios de Occidente y marcaron fuertemente a los nuevos regímenes emergentes de las crisis 
imperiales. Paralelamente, el seguimiento de la saga individual y/o grupal podía acrecentar nuestra comprensión no sólo de los procesos macro que se sucedieron luego de la ruptura formal de los lazos institucionales entre ciertos espacios americanos y sus metrópolis sino también proporcionarnos indicios, ya en el plano del microanálisis, sobre las readaptaciones, las resistencias o las modificaciones en las estrategias que tales individuos pergeñaron ante los mismos. En tercer lugar, era factible que iluminara aspectos relativos a los "modos" en que estas sociedades internalizaron los nuevos códigos y lógicas políticas. Por ende, apostamos al género biográfico para recuperar las voces de algunos de sus protagonistas y observar cómo entendieron, procesaron, transmitieron y actuaron en aquella nueva "gramática del poder" que se comenzaba a desplegar a lo largo de las luchas independentistas.

La pretensión de este primer avance no fue recuperar la "totalidad" de una o unas vidas sino poner a foco algunas facetas de la trayectoria de unos actores sociales que se proyectaron políticamente. Dicha recuperación se hizo desde una perspectiva interna que -como lo ha marcado excelentemente Isabel Burdiel (2004, p. 23)- trascendiera la separación formal que la teoría liberal estableció entre lo privado y lo público, ya que una dimensión impregnaba en la práctica a la otra y viceversa.

Pero existieron otros supuestos en este intento de tránsito por el género biográfico en clave transatlántica. Estas prácticas entre lo privado y lo público se exploraron a partir de unos sujetos que vivieron, como en el caso que nos ocupa, en ambos lados del océano y adquirieron visibilidad a partir de sus específicas lecturas sobre las dinámicas que se estaban desarrollando en metrópolis o espacios cuyas comunidades políticas se resignificaban. Las experiencias de unos y otros espacios retransmitían y transfiguraban conceptos, modelos y prácticas, permitiéndonos perfilar a través de tales "vidas" la compleja tensión entre el mundo de sus ideas y sus necesidades cotidianas al interior de una densa lucha por el poder.

En esta dirección convalidamos lo afirmado por María Sierra (2010), sobre

la utilidad de la historia comparada y transnacional para entender cómo, en diversos ámbitos territoriales y políticos, los modelos de representación propios del liberalismo occidental compartieron numerosas fuentes culturales y unos comunes mecanismos de desarrollo, si bien, a través de procesos concretos de adaptación local, terminaron adquiriendo distinta lectura y encarnación institucional (p. 98).

Junto a los análisis que tendieron a priorizar en la interacción Europa-América Latina unas tradiciones exclusivamente anglosajonas o francesas, los estudios en cierto sentido pioneros de François-Xavier Guerra alertaron sobre la necesidad de reconocer en la configuración de los espacios iberoamericanos también las "marcas" dejadas tanto por la vía española como por la portuguesa al nuevo régimen, aun después de los procesos revolucionarios de las primeras décadas del siglo. ${ }^{1}$ Desde esa perspectiva sumamos nuestra voz a la de Sierra (2010) para cuestionar "la idea ex-

${ }^{1} \mathrm{Si}$ bien existe una extensa bibliografía al respecto, desearía destacar un excelente acercamiento realizado por Guerra (1994, pp. 195-228); Pereira (1994, pp. 169-194); Portillo (2006); Elliott (2006); Rodríguez (2005). 
tendida de que los procesos de independencia colonial debilitaron hasta su práctica consunción los lazos políticos entre España y las nuevas naciones iberoamericanas". Al tiempo que confirmamos con ella que

las rupturas diplomáticas, los distanciamientos institucionales y la distorsión de los tráficos económicos, no implicaron necesariamente la desaparición de unas transferencias ideológicas y culturales, que tuvieron en las acciones personales e individuales su principal cauce de desarrollo, y cuyo radio de acción permitió también la triangulación de ideas y modelos con la América anglosajona y la Europa occidental (pp. 99-100).

Más aún, creemos que desde el caso podremos detectar cómo más allá o más acá del conflicto, un conjunto de actores sociales y políticos rearticularon una y otra vez sus vínculos y les dieron nuevos significados.

La perspectiva transatlántica obligó no sólo a replantear las interpretaciones de las luchas independentistas en sí mismas sino que puso al descubierto, entre otras cuestiones y desde una perspectiva renovadora, que el complejo proceso de paso del antiguo régimen a uno asentado en la soberanía popular conmovió y modificó ambas márgenes oceánicas. Paralelamente valorizó el papel desempeñado por los intercambios e interacciones, consensuales o conflictivas, entre unos imperios y sus colonias precedentes, entre elites de unos espacios y otros, y entre sujetos que irían redefiniendo su lugar y sus dinámicas tanto en las metrópolis como en los nuevos contextos políticos.

Alejada de una mirada simplificadora, nuestra búsqueda se orientó, como lo ha señalado Sierra (2010), a pensar a las transferencias culturales no como un proceso

en absoluto lineal y acabado, supuestamente originado en un único foco protagonista y miméticamente implantado en otro espacio receptor, sino más bien como un flujo zigzagueante, en cuanto que nunca cerrado y menos voluntariamente controlado por el emisor, en el que intervienen tanto las intenciones y necesidades de la sociedad de llegada, su capacidad de reformulación y relectura, como la cultura política de los que han servido de transmisores (pp. 103-104).

En ese trasiego transatlántico ¿qué lugar tendría nuestro actor? Como se planteaba en el epígrafe, nuestra biografía propone un cierto registro "coral", poniendo en tensión la "singularidad" del mismo (Loriga, 1996, p. 230) a fin de que deje al descubierto la complejidad de los fenómenos emergentes (Dosse, 2007, p. 407), sin creer que tal sujeto histórico responde a un modelo de racionalidad limitada (Levi, 1989, p. 1326) ni que su destino individual se corresponde necesariamente con un destino colectivo (Revel, 2005, p. 225). Sin duda, uno de los interrogantes más acuciantes se orientó a precisar cuál fue la "capacidad de acción" de tales sujetos frente a los enormes desafíos que suponían la crisis del proyecto imperial y la emergencia de nuevos estados, así como las condiciones que tuvieron para incidir en su entorno.

La experiencia biográfica que introducimos es la de un diputado americano a las Cortes Españolas en la coyuntura del levantamiento de Riego. Creemos que el caso de Francisco de Magariños nos permite focalizar unas coyunturas históricas de alta significación tanto para la realidad 
española (1810-1823) como para la rioplatense y la uruguaya, en particular (1810-1825). Pero también ofrece otras alternativas, ya que nos coloca, en primer lugar, frente al desafío de caracterizar a este sujeto y las particulares modalidades de su estatuto de representante. En segundo lugar, nos impulsa a determinar el papel desempeñado por él y -a través de él- por su grupo de referencia y de pertenencia así como a explorar las estrategias de alianzas a las que sus miembros se orientaron con miras a afianzar o bien la continuidad de la monarquía, o bien la independencia al interior de la pugna entre Buenos Aires -en su intento de desempeñar un papel hegemónico sobre el Río de la Plata-, Brasil, España y Portugal. Finalmente, hace posible acercarnos a este sujeto portador de una determinada cultura política que se transforma y resignifica al calor del debate y las prácticas con otros, posiblemente generacionalmente afines, configurando a través de sus vivencias una discursividad y unas acciones que expresan sus modos de entender y transmitir de un lado al otro del Atlántico las lógicas del poder.

\section{Puntos de partida de una experiencia de vida}

Los primeros indicios los proporcionan los ecos que nos llegan de voces cercanas a él y permiten el seguimiento del juego de los vínculos en los que se halla inmerso. En esta dirección estimamos que resultan relevantes aquellas relaciones que determinados grupos mercantiles -dentro de los cuales se integra nuestro personajedesplegaron en ese complejo proceso de desestructuración del proyecto metropolitano español y ante la emergencia de nue- vos espacios de poder pero también de competencia.

Francisco de Borja Magariños Cerrato opera como una llave para comprender cómo impactó la revolución liberal española sobre el Río de la Plata, y particularmente sobre ciertos sectores de sus elites.

La plaza de Montevideo, su lugar de origen, se convierte en un escenario privilegiado por el papel estratégico que desempeña tanto en el conflicto que enfrenta a Buenos Aires con la antigua metrópoli como ante la Corte de Brasil, luego de la ocupación militar de dicha ciudad por las tropas imperiales en enero de 1817. Al interior de esta última -en la que terciarían las coronas ibéricas para la restitución de la plaza y su campaña- es posible explorar no sólo la diversidad de intereses de los grupos que se confrontan entre sí sino también la complejidad de las alianzas y los objetivos antinómicos que los colocan o bien a favor de la reestructuración de los lazos con España o bien involucrados en movimientos independentistas nuevos, cuando no en su integración a la corona brasileña.

¿Qué guiaba a estos miembros de las elites locales a identificar su destino con la monarquía "reinventada" por el nuevo orden liberal?, ¿era sólo la pervivencia de los contactos y de las estrategias de acumulación que los habían enriquecido en el pasado colonial?, ¿cómo los afectaba "el hecho revolucionario" y sus consecuencias?, ¿tenían la convicción de que la monarquía podía operar como una herramienta de transformación pacífica tanto de las instituciones como de las prácticas políticas?, ¿qué factores incidieron en sus estrategias de alianza? Por el contrario, ¿cuáles fueron las condiciones que los condujeron a plantearse la necesidad de una

\section{()(1) $(9$}


independencia que habían bloqueado anteriormente?, ¿fueron las orientaciones que la revolución liberal española imprimió a sus políticas en el área las que impactaron negativamente y los condujeron a un cambio de perspectiva?, o bien ¿fue la ocupación brasileña y su devenir la que los impulsó hacia estrategias independentistas?, ¿qué percepción tenían sobre los nuevos códigos liberales y el republicanismo?

El caso dispara una multiplicidad de interrogantes, algunos de los cuales pretendemos abordar a fin de dar un paso más en el análisis de este complejo proceso que opera en dos contextos regionales: el ibérico y el rioplatense.

Presentemos a nuestro actor. Francisco de Borja nació en Montevideo el 10 de marzo de 1796, dentro de una trama familiar que -desde ambas ramas- se integró a la burocracia imperial civil y militar que operaba ya en la península, ya en las colonias.

No es un dato menor que su abuelo paterno fuera Juan Antonio Magariños, escribano público gallego, asentado en la Isla de León (Cádiz). Este, conjuntamente con su mujer andaluza, Juana Ballinas, y sus hijos pequeños, se instaló en Buenos Aires (1773). Él formaba parte de ese proceso de renovación burocrática que en la etapa borbónica expandió no sólo la economía metropolitana sino las nuevas políticas imperiales (Caula, 2002, p.13). Como en otras realidades americanas y europeas, estos grupos apostaron a la formación de sus hijos en colegios, universidades y academias que se abrirían cual canales de ascenso social (Betancur, 1996, pp. 107, 109; Betancur, 2011, p. 221). ${ }^{2}$

\footnotetext{
${ }^{2}$ Dicho autor destaca, entre otros, la preocupación de esta elite comercial por la formación de sus hijos
}

En el espacio bonaerense se llevó adelante la socialización inicial de su padre, Mateo, quien más tarde participaría del ambiente intelectual de Chuquisaca, donde se graduó como abogado en 1789. ${ }^{3}$ Siguiendo las pautas culturales de esas elites, Mateo Magariños Ballinas contrajo matrimonio con Manuela Hermenegilda Cerrato (1792), perteneciente también ella a un grupo notable bonaerense, ya que sus padres eran Manuel Cerrato, teniente de Dragones, y Josefa Eulalia Chorroarín (Goldaracena, 1978, pp. 167-168).

La incorporación de su padre a la burocracia civil española en Montevideo desempeñando diversas funciones (cabildante, escribano, abogado fiscal de la gobernación, etc.) favoreció sus vínculos con el mundo de los negocios (Mora, 1919, pp. 441-442). Mateo, apelando a los espacios y figuras jurídicas que le brindaba la estructura mercantil colonial, fue ampliando su círculo de alianzas y engrosando su patrimonio. Formó parte de una configuración mercantil que desde la colonia integró los mercados altoperuanos, de Nueva Granada, Brasil, Montevideo y Buenos Aires con los puertos peninsulares, y que utilizó también las patentes de corso para lograr mayores ganancias. De este modo, su relativamente escasa fortuna inicial ${ }^{4}$ se vio rápidamente incrementada por su activa participación en el tráfico de importación y exportación que

y resalta la intervención de Mateo Magariños en pos de la educación desde la escuela pública de la ciudad.

${ }^{3}$ Hay algunas discrepancias en las fechas y el lugar entre los biógrafos. Véanse Mora (1919, pp. 438-439) y Goldaracena (1978, p. 168).

${ }^{4}$ Según algunos autores, contribuyó al mismo inicialmente la herencia de su esposa (Betancur, 1996, p. 108). 
se desarrollaba a través de aquellos mercados tanto desde su papel de comerciante como de propietario de buques. Con los años, a los contactos logrados en América y en Europa, sumó los de África Occidental (Angola), donde intervino en la trata de esclavos.

A principios del siglo XIX sus negocios en el mercado internacional se desarrollaban desde grandes almacenes y depósitos de frutos del país y del extranjero. Ellos se complementaban con una gran panadería, una quinta de legumbres y frutas, así como dos importantes saladeros y estancias (Goldaracena, 1978, pp. 168-169; Mora, 1919, pp. 443-447).

La fortuna familiar abrió nuevas posibilidades de integración y ascenso a su engrosada familia, teniendo en cuenta que Francisco fue uno de los doce hijos del matrimonio. Varios de los varones -dando continuidad a las lógicas de estas elites- se volcaron o bien a la actividad civil o bien a la militar en la búsqueda de fortuna u honores en la península, camino que tomaría más tarde el propio Francisco. Sus primeros años transcurrieron en un espacio de mayor proximidad, ya que siguiendo en parte los pasos de su padre, se puso en contacto con el mundo cultural de la capital virreinal (Buenos Aires). De la mano de su tío materno, Luis Chorroarín, director desde 1785 del Colegio de San Carlos -uno de los centros coloniales más prestigiosos de la época y cuyas aulas también había transitado Mateo- fue ampliando tanto sus conocimientos sobre doctrinas y nociones políticas como sus contactos personales y grupales. El presbítero, altamente imbuido de las lógicas liberales, tenía vinculaciones directas no sólo con los núcleos intelectuales del momento, sino también con los políticos, y debió operar junto a otros clérigos y letrados como mediador entre la cultura de elite y la cultura popular (Di Stefano, 2002).

La coyuntura introdujo a nuestro actor rápidamente en la vida pública y dejó en él profundas marcas. El primer episodio que enfrentó el joven fue el de la lucha militar al producirse las invasiones inglesas. En 1806 vivió la toma de la plaza de Buenos Aires por los ingleses y su reconquista. Operó, siendo casi un niño, como ayudante mayor del Cuerpo de Cazadores Urbanos, y se incorporó al proyecto de reconquista liderado por Liniers en un batallón sostenido por su padre (Mora, 1919, p. 477). Frente a la liberación de Buenos Aires, los ingleses no dudaron en ocupar rápidamente la población de Maldonado en la Banda Oriental y tomar, en febrero de 1807, la propia Montevideo en una operación naval y terrestre conjunta. La caída de Montevideo, sucedida rápidamente por las decisiones del Cabildo de Buenos Aires de destituir al virrey Sobremonte y designar como tal a Liniers, sentó un significativo precedente en la "autodeterminación" del pueblo de Buenos Aires.

El control sobre la Banda Oriental, pese a la resistencia de Liniers, permitió a los ingleses utilizar a Montevideo como base para el contrabando, logrando que sus mercaderías penetraran en las colonias españolas.

Los ingleses aspiraban a sostenerse en la plaza y por ello necesitaban generar, especialmente entre las elites, cierto consenso, por lo cual estimularon las tácticas propagandistas a través del periodismo. En esta dirección dieron vida a La Estrella del Sur, publicación que se convirtió en el primer periódico local. Este venía a

\section{()(1) $(3$}


sumarse a un conjunto de manuscritos, panfletos, gacetillas que habían comenzado a circular en los años precedentes y que respondían -como otras publicaciones europeas o americanas que llegaban al puerto- a las crecientes demandas de información y alimentaban el debate (Frega, 2007, p. 182).

La ciudad, convertida en un eje económico importante en la estrategia inglesa, sirvió también como base de operaciones desde la que se impulsó una nueva invasión a Buenos Aires en junio. Sin embargo, la exitosa defensa de la misma y las pérdidas sufridas por los británicos, le permitieron a Liniers exigir la rendición de las fuerzas, su retiro del Río de la Plata y la devolución al virreinato del Río de la Plata de las ciudades tomadas.

La experiencia militar y política que conllevaron las invasiones no sólo conmocionó la realidad del virreinato del Río de la Plata, sino de sus grupos dirigentes.

¿Cómo afectaron estos acontecimientos y la posterior imposición de José Bonaparte por los invasores franceses en lugar de Fernando VII, a la familia Magariños y al núcleo de comerciantes de los que formaba parte Mateo?

Este y su núcleo de asociados y amigos tenían una buena información sobre lo que estaba sucediendo en los espacios virreinales latinoamericanos y en la metrópoli a partir de su red mercantil. Por sus prácticas como comerciantes o patrones de buques pero también por su formación académica, como era el caso de Mateo, estos hombres habían internalizado en su cotidianeidad el derecho natural y de gentes, así como las doctrinas contractualistas que circulaban. Por ende, el iusnaturalismo operaba entre ellos como un sustrato sobre el que fundaban la legitimidad de su accionar social o político, pese a sus divergencias (Chiaramonte, 2000, p. 52). Entre 1808 y 1809 habían comenzado a esbozar sus propias interpretaciones sobre una coyuntura en la que operaban concomitantemente las tensiones provocadas tanto por las acciones expansivas portuguesas ligadas a la instalación de la familia real en Río de Janeiro como por potenciales intervenciones inglesas.

En setiembre de 1808 algunos de estos actores participaron del cabildo abierto montevideano que derivó en la creación de una Junta. Esta no sólo desconoció la autoridad del virrey Liniers -acusándolo de proclividad hacia Napoleón- sino que comenzó a gobernar con autonomía tanto frente a las autoridades de la península como ante diversas ciudades del virreinato y representantes extranjeros.

La Junta legitimó su accionar apelando "a la antigua Constitución del Reino y al derecho natural a la conservación”, aunque también a la igualdad entre "españoles europeos" y "españoles americanos" (Frega, 2007, p. 190). Uno de los defensores de esta posición fue Mateo Magariños, quien no sólo participaba de una concepción bastante extendida sobre el origen contractual del Estado sino también sobre el valor de la "representación del Pueblo" con miras a garantizar toda "sucesión legítima” (Frega, 2007, p. 191). Si bien la experiencia fue relativamente breve, ${ }^{5}$ dejó sus marcas. Tales planteos reaparecerían una y otra vez en el debate. En esta primera etapa Mateo Magariños y sus aliados reafirmarían su fidelidad a la

${ }^{5}$ En junio de 1809 aquella se disolvió obedeciendo los mandatos de la Junta Central Suprema y Gubernativa. 
corona $^{6}$ y avalarían al Consejo de Regencia y a las autoridades designadas para la gobernación de Montevideo - primero de Elío y luego Gaspar Vigodet. Sin embargo, no desaparecerían de sus miradas o de sus concepciones ni el principio de la "retroversión” de la soberanía ni el de igualdad de derechos de los pueblos.

¿Cuáles fueron, en esta instancia, las vivencias de Francisco? Sin duda debió estar tensionado entre las perspectivas de su padre y las de su tío: Luis Chorroarín. Este, que estaba convencido de la necesidad de imponer desde la crisis imperial la tesis de la "reasunción de la soberanía por parte de los pueblos" -a diferencia de Mateo-, se integró rápidamente a las asambleas que dieron vida a la Primera Junta en Buenos Aires.

La institución emergente, marcando un quiebre con los sucesos de Montevideo de 1809, no sólo no se disolvería sino que se orientaría tanto hacia la ruptura de los vínculos con la antigua metrópoli como hacia la búsqueda de alternativas constitucionales para ese espacio (Mora, 1919, p. 440).

Ante tales perspectivas Francisco pareció volcarse inicialmente a favor de las argumentaciones paternas. Mateo no sólo operó activamente desde el Cabildo mon-

\footnotetext{
${ }^{6}$ Pese a la angustia que lo embarga por las dificultades que enfrenta esa sociedad en la coyuntura de mayo y junio de 1811, Mateo plantea a su hijo Francisco la necesidad de una rápida sanción de la Constitución para que el orden retorne a esos espacios y se dirima la cuestión soberana. Al mismo tiempo ratifica para ese momento su aval a la monarquía: "y sera forsoso conservarnos, y morir antes q.perder la dignidad de vn Pueblo Español y leal á su soberano". Véase Archivo Artigas (1963, t. v, p. 44). Relación diaria de los acontecimientos ocurridos en 1811 desde el 20 de mayo al 10 de junio en Montevideo que Mateo Magariños envía a su hijo en Madrid.
}

tevideano avalando el vínculo con la metrópoli, sino que se involucró en la defensa armada de la ciudad cuando las tropas bonaerenses la sitiaron. Volvía a ratificar frente a la postura de Buenos Aires -que intentaba trasladar hacia los territorios del antiguo virreinato la concepción de una soberanía indivisible y jerárquicamente estructurada- el derecho de los pueblos a redefinir en igualdad de condiciones su propia articulación soberana (Frega, 2007, p. 191). En consecuencia, colaboró con su patrimonio para la organización del Batallón de Comercio y colocó a su hijo Francisco en él para defender a Montevideo de sus sitiadores.

Su predicamento dentro de la elite montevideana y sus dotes intelectuales debieron tener un papel importante a la hora de ser designado, primero, representante ante el príncipe regente de Brasil en 1813 en búsqueda de apoyos o, luego, frente al general Alvear, responsable del sitio y bajo cuyas órdenes se ocuparía la plaza en 1814 (Mora, 1919, pp. 452-453). ${ }^{7}$

A partir de ese momento se inicia para varios de los integrantes del grupo de Mateo Magariños el tiempo del exilio en la corte portuguesa. Hay cierta convergencia en las fuentes para señalar que Francisco fue enviado entonces a continuar sus estudios en España.

\section{El viaje hacia la península y la conversión en "representante de"}

No hemos detectado si en la península alcanzó algún título profesional pero sí que

${ }^{7}$ Véase también el detallado relato de esos acontecimientos en Betancur (1999, t. II, particularmente pp. 146-213).

\section{()ㅜ(1) $(9$}


Francisco de Borja fue, desde España, uno de los administradores de los negocios paternos, así como de los de otros miembros de la red. Esta, gracias a los vínculos y alianzas desarrolladas en el campo económico y político, continuó llevando adelante sus estrategias mercantiles más allá de los problemas que le suscitaban tanto la revolución bonaerense como la caída de Montevideo en manos de las tropas porteñas y, posteriormente, brasileñas. La lógica mercantil atravesaba el debate político y los obstáculos que este imponía al grupo. $\mathrm{Ni}$ siquiera la forzosa salida de Mateo Magariños hacia Brasil y las expropiaciones a las que fue sometida parte de sus bienes, impidieron que sus agentes y los de los otros miembros de la red -merced a la puesta en acto de sus lazos personales o políticos- continuaran obteniendo permisos tanto de los gobiernos bonaerenses como de los encargados de negocios españoles en Río de Janeiro o en otras plazas latinoamericanas (Caula, 2009, p. 9). Esto pone en evidencia, una vez más, la ductilidad de estas tramas para adaptarse a contextos cambiantes ya en el plano económico, ya en el político y, en esta última dirección, más allá de su propia toma de posición.

El indicio más firme señala que Francisco ya estaba residiendo en Madrid en 1817 (María, 1879, p. 112). En esa etapa se había afirmado el control portugués de Brasil sobre la antigua Banda Oriental, y el Congreso de Tucumán, en las Provincias Unidas del Río de la Plata, había declarado la independencia. Esto no impidió que continuaran existiendo contactos entre estos espacios y la corona española, contactos que en muchos casos atrajeron fuertemente la atención de las autoridades metropolitanas. La correspondencia iba precedida o sucedida de un fluido intercambio de informaciones en las que predominaba un reiterado diagnóstico sobre divisiones internas en los espacios americanos que estimulaban la interpretación de impotencia o dificultad para autogobernarse. Ello potenció la convicción de la dirigencia española a lo largo del reinado de Fernando VII, y más allá de los avatares de la revolución liberal de 1820 , de que debía darse continuidad a la política orientada a reconquistar las ex colonias (María, 1879, p. 113; Caula, 2009, p. 3).

Desde Madrid, Francisco incrementó las interacciones con su padre y con los montevideanos y porteños adversarios de la revolución de Buenos Aires y emigrados a Río de Janeiro. En dicha ciudad, la embajada de España se había convertido en una pieza central en el juego político entre la metrópoli y sus potenciales aliados emigrados. Un papel relevante tuvo en ello, especialmente desde 1817, el marqués de Casa Florez. Este fue elegido para dirigirla en virtud de sus conocimientos del medio y sus relaciones con los "americanos". Casa Florez desplegó papeles significativos tanto en relación con la corte portuguesa como frente al virreinato del Perú, con el que mantenía contactos permanentes, e hizo circular información privilegiada hacia ese virreinato y hacia la metrópoli. En esa dinámica geopolítica que mostraba - pese a los avances del ciclo revolucionario- la fuerte interacción entre los sectores y áreas afines al proyecto imperial, el marqués tuvo ciertos logros aun cuando no pudo neutralizar ni las injerencias de la infanta Carlota en el área rioplatense ni la invasión portuguesa a la Banda Oriental sin el consenso del rey.

Para el embajador en Río de Janeiro había emergido un espacio clave afín a sus 
propósitos y típico de las formas asociativas de antiguo régimen: las tertulias de Mateo Magariños. Desde su llegada a la corte portuguesa, Mateo no sólo conformó un "círculo de españoles exilados" leales a Fernando VII sino que lo puso en relación con la embajada. Dicho círculo, que operaba al interior de las tertulias organizadas por el anfitrión, se había convertido en un importante canal de información a través de sus redes de relaciones ya en la Banda Oriental, ya en España. Pero también era funcional para la elaboración de planes para la recuperación del virreinato del Río de la Plata.

Si bien existió un número considerable de propuestas de este tipo (véase Mariluz, 1958, pp. 99-180), nos centraremos en aquellas estrategias pergeñadas desde Madrid por el joven Francisco, quien se asumía como "buen español preocupado por la pacificación”. Este, siguiendo una línea de acción ya transitada por uno de sus antecesores en la primera etapa de Cortes (1810-1814) -Rafael Zufriátegui-, ${ }^{9}$ reiteraba la convicción de las autoridades y de los grupos mercantiles montevideanos de que sólo la ayuda militar española permitiría recuperar el control de aquel espacio. Francisco, conocedor de los preparativos de una expedición hacia el área rioplatense (1819), elaboró sucesivos memorandos con informaciones vitales sobre la flota marítima de los rebeldes de

\footnotetext{
${ }^{8}$ Fondo Magariños. Caja 107, carpetas 14, 15, 16 ; caja 108 , carpetas $1,2,3,4,5$; caja 109 , carpetas 9, 10; caja 111, carpetas 3, 5. Archivo General de la Nación (AGN), Uruguay.

${ }^{9}$ Véase, entre otros, Betancur (1999, pp. 147152). Este autor detalla los diferentes intentos, con sus escasos resultados, llevados adelante por el diputado Zufriátegui entre 1811 y 1814.
}

Buenos Aires y Chile en el Pacífico; estrategias para lograr el abastecimiento de víveres y caballadas ante el desembarco de las tropas e, incluso, una propuesta de reorganización político-administrativa que creaba una Capitanía General de Montevideo. ${ }^{10}$ Pero también explicó, desde su perspectiva, los conflictos que atravesaban a esos pueblos:

Los que reasumiendo el mando en la Primera Junta que se instalara en Buenos Ayres [sic] en mayo de 810, substituyeron, bajo el falso y aparente bien de la Patria, la libertad engañosa que hizo sublevar aquellas tranquilas Provincias solo pensaron... en ver de cambiar por este medio sus pequeñas fortunas, o hacerse visibles sobre la ruina de tantas infelices familias sacrificadas a su desmedida ambición. Esto es lo que ha suscitado igualmente, tantas y tan continuadas contra revoluciones para adquirir el mando o para perpetrarse en él; y de ellas resulta, que destrozados por el continuo choque de las facciones y por el monopolio de los Estranjeros [sic] se hallan en el día en una anarquía completa. ${ }^{11}$

Francisco intentaba detectar -frente a una situación que por momentos resultaba caótica- actores colectivos o individuales que pudieran servir de anclaje a una política de recuperación por parte de la corona de esos territorios:

\footnotetext{
${ }^{10}$ Fondo Magariños. Caja 107, carpeta 1. AGN, Uruguay.

${ }^{11}$ Memorial del 30 de agosto de 1819 presentado al general que emprendería la expedición de pacificación del Río de la Plata, conde de Calderón. Fondo Magariños. Caja 107, carpeta 16. AGN, Uruguay.
}

\section{()(1) $(9$}


Los partidos que con este motivo se mueven [sic] diariamente son tantos como cabezas tiene la Revolución, pero con la diferencia, que los unos creyéndose perdidos inexcusablemente, y odiando el nombre Español, no quieren someterse al Rey Nuestro Señor por más que se hallen convencidos de que les es imposible lograr su deseada Independencia, y estos preferirán comprometer al Pueblo o sugetarlo [sic] a una potencia Extranjera, como lo solicitaron ya de la Gran Bretaña, en el año 15, por medio de los diputados Belgrano y Rivadabia [sic], temiéndose la llegada de la Expedición que salió con el general Murillo; otros, y no en pequeño número, desengañados de la farsa en que los metieron, aspiran formalmente a reunirse a la Madre Patria, porque ven impugnemente [sic] arruinar al País y las fortunas de sus habitantes pero la necesidad los obliga a seguir aquel partido, y otros por fin por no perder sus comodidades se mantienen en una neutralidad ó egoísmo de que han savido [sic] sacar un partido ventajoso a sus intereses. ${ }^{12}$

El joven estaba convencido de que importantes sectores se unirían a la causa del rey si se les prometiera conservar grados y empleos, así como condiciones de pacificación. Para incrementar las adhesiones proponía concientizar a las dirigencias sobre los beneficios que aportaría apoyar la restitución del vínculo con la metrópoli: "sería oportuno una Imprenta bien manejada, pues esto influye sobremanera, como que ha sido la mejor arma de la que se han valido y valerán los trastornadores del orden".

${ }^{12}$ Fondo Magariños. Caja 107, carpeta 16. AGN, Uruguay.
Tal estrategia se vería potenciada si además se atraía a las mujeres cuya lealtad y adhesión a la causa "española" consideraba determinantes: "el bello sexo que tanta influencia tiene en aquellos países, es en su totalidad del partido del Rey Nuestro Señor, y el que ha mantenido y sostiene a tantos desgraciados prisioneros, cuya suerte reclama toda clemencia para que la usen con ellos, porque de lo contrario serán víctimas de los malcontentos". ${ }^{13}$

Su optimismo era tal que incluso pensaba que podía atraerse hacia el campo realista al propio Artigas por su claro enfrentamiento con la corona de Brasil y con el gobierno de Buenos Aires. En un escrito bajo el seudónimo de un "amante del sosiego y la tranquilidad" -comentando un bando del general Rondeau- Francisco insistía en su creencia de que "no todos los ciudadanos quieren tomar las armas contra las tropas del Rey".

Paralelamente impulsaba a clarificar el concepto de pueblo que Rondeau y la dirigencia bonaerense podían estar utilizando: "si por pueblo entiende solo los Americanos es una falsedad... o quiere con esta lisonja seducir al Populacho". ${ }^{14}$

Si bien el joven reiteraba en esta instancia sus criterios de igualdad entre americanos y españoles, no escapaba a una lógica notabiliar en su mirada frente al pueblo. Desde tales perspectivas y en la coyuntura, se sumaba al bando defensor

${ }^{13}$ Fondo Magariños. Caja 107, carpeta 16. AGN, Uruguay. La actitud de las mujeres había sido señalada anteriormente por otros observadores y algunas publicaciones como El Sol de las Provincias Unidas (1814). Véase Betancur (1999, p. 191, notas 313 y 314).

${ }^{14}$ Fondo Magariños. Caja 107, carpeta 16. AGN, Uruguay. 
de una intervención de España por cuanto presuponía claros los objetivos de sus potenciales protagonistas:

Todos los españoles que vienen reconocen que sus verdaderos intereses, es destronar la iniquidad, la tiranía, la perfidia de tantos insensatos filósofos libertinos, Francmasones como alberga Buenos Ayres en su seno... Vienen animados de un sano entusiasmo por la Religión, por el Rey y por la verdadera Patria. ${ }^{15}$

El análisis implicaba una clara toma de posición frente al debate del momento. La causa de la recuperación colonial se asentaba en la alianza de la monarquía y la Iglesia, cual símbolos identitarios de "la patria".

Si inicialmente la revolución liberal española de 1820 bloqueó estos proyectos, su triunfo vino a marcar un punto de inflexión. En principio, porque al calor de la restitución de la Constitución de 1812 volvieron a sesionar las Cortes y se restablecieron los Ministerios de Gobernación y Ultramar, las tramas institucionales encargadas de recuperar el diálogo y las interacciones formales entre la metrópoli y las colonias. Luego, por cuanto revivieron las esperanzas de recuperar los dominios americanos a través de nuevas vías de negociación. Tanto Bernardino Rivadavia, en representación del Río de la Plata, como los comisionados de Chile, Venezuela y Nueva Granada intentaron-desde Londres- retomar contactos con el gobierno español. El joven diputado Magariños Cerrato se puso a disposición del proyecto, gestionando pasaportes y entrevistas a través de sus vínculos con el

${ }^{15}$ Fondo Magariños. Caja 108, carpeta 1. AGN, Uruguay.
Ministerio de Ultramar y la embajada (María, 1879, p. 114).

Fernando VII y sus consejeros, evaluando las condiciones que ofrecía la situación, elaboraron un Manifiesto destinado a revitalizar los vínculos coloniales. Los comisionados regios serían los encargados de informar a los habitantes de ultramar que el rey había jurado "espontáneamente" la Constitución de Cádiz, exhortándolos a enviar diputados a las Cortes.

La nueva coyuntura también incidió de manera significativa en la vida personal de Francisco Magariños, ya que este resultó electo diputado a las Cortes en representación de la Gobernación de Buenos Aires. Como había sucedido en la etapa 1811-1814, aquella metrópoli, que no estaba dispuesta a perder sus vínculos coloniales, mantuvo el criterio de tener en sus Cortes representantes americanos.

Con las mismas tácticas de entonces, Francisco fue elegido diputado suplente el 29 de mayo de 1820 por los 16 votos de los ciudadanos bonaerenses y chilenos residentes en España. El 5 de julio de 1820 se aprobaron sus poderes y juró al día siguiente.

Sin embargo, debió percibir algún nivel de cuestionamiento o experimentar cierta sensación de "ilegitimidad" por cuanto a la magra base electoral que lo había convertido en representante se sumaba el hecho de que dicha representación se hacía en nombre de Buenos Aires, espacio con el que mantenía un fuerte conflicto. Por ende, el 11 de julio de 1820 se presentó ante las Cortes poniendo en cuestión su representatividad, ya que sus opiniones políticas se diferenciaban de las bonaerenses. En su exposición afirmó haber aceptado la representación de una provincia disidente por cumplir con "el

\section{()(1) $(3$}


derecho de obediencia, imprescindible en todo buen ciudadano español". ${ }^{16}$ Estaba convencido de que las Cortes debían ser magnánimas con el mundo americano y por lo tanto solicitó el otorgamiento de una amplia "amnistía general para toda la España Ultramarina”, acompañada de una puesta en libertad "de todas aquellas personas que se hallen presas o detenidas por motivos de disidencia, u otros a que haya dado margen la revolución”. ${ }^{17}$ En tanto esta segunda proposición siguió por otros carriles, su solicitud de ser apartado del cargo fue rechazada.

\section{El representante a Cortes entre la revolución liberal española y los proyectos independentistas de la Provincia Oriental.}

El "grupo de Río de Janeiro", si bien decepcionado por la frustración de la expedición armada, intentó enfrentar positivamente los cambios producidos tanto en la metrópoli como en el propio Portugal al calor de los movimientos liberales. Sin embargo, ni la misión de los comisionados enviados por España ni el levantamiento del príncipe Pedro en Brasil favorecieron la "devolución" de la Banda Oriental a

\footnotetext{
${ }^{16}$ Series Electorales. Serie documentación Electoral, 7, núm. 38; Diarios de Sesiones de Cortes, 5 de julio de 1820, p. 10; 11 de julio de 1820, p. 3. Archivo de Cortes de Diputados (ACD); Fondo Magariños. Caja 108, carpeta 2. Nota 22 de julio de 1820. AGN, Uruguay.

${ }^{17}$ Diarios de Sesiones de Cortes. 11 de julio de 1820, pp. 32-33; 17 de septiembre de 1820, p. 1075. ACD. La base de su argumentación residía en que en esta nueva coyuntura liberal debía demostrarse que la "España europea quiere cicatrizar las llagas abiertas por el despotismo”, volviendo a la unión.
}

España. Por el contrario, mientras los primeros fracasaron ampliamente en sus gestiones pacificadoras en toda el área, la segunda situación consolidó el dominio de la Provincia Oriental por parte de los lusitanos. Pese a ello, estos actores consideraron que la representación de Francisco podía ser funcional a sus objetivos y, más allá de las dificultades precedentes, consensuaron su elección como diputado suplente por Buenos Aires para el periodo 1820-1821 y, por su intermedio, dieron su aval a la "Augusta Asamblea que representaba al Imperio Español en ambos mundos". 18

Los miembros del grupo debieron estar contestes de la fragilidad de la representación de Francisco y, ante la imposibilidad de convocar a elecciones, en distintos momentos de 1821 hicieron llegar a las Cortes -cual "españoles de ambos hemisferios, vecinos de la ciudad de Montevideo y su jurisdicción territorial"- su respaldo al nombramiento del diputado, reconociendo sus poderes y convalidando su continuidad para el periodo 1822-1823. ${ }^{19}$ Evidentemente, el consenso logrado por Francisco no se redujo al círculo riograndense sino que fue ampliándose tanto en la Banda Oriental como en Río de Janeiro, y llegó a incluir a algunos antiguos seguidores de Artigas.

El apoyo de los artiguistas seguramente fue resultado tanto de las gestiones realizadas por el diputado para lograr el envío de fuerzas armadas a fin de liberar el territorio de la ocupación portuguesa como de

${ }^{18}$ Fondo Magariños. Caja 108, carpeta 3, 26 de abril de 1821. Petitorio firmado por 109 ciudadanos. AGN, Uruguay.

${ }^{19}$ Fondo Magariños. Caja 108, carpeta 3. AGN, Uruguay. 
aquellas en pos de la amnistía para los prisioneros que estuvieran dispuestos a jurar la Constitución. En la correspondencia entre prisioneros artiguistas y Mateo Magariños así como con el marqués de Casa Florez aparecen algunos indicios de los contactos y las aspiraciones de los primeros. Un ejemplo de ello se observa en la carta que Vicente Pazos le dirige al marqués de Casa Florez el 18 de agosto de 1820:

Me apresuro á poner en el superior conocimiento de V. E., que habiendo tenido muchas conferencias con D. Manuel Artigas, hermano del General, he descubierto en él disposiciones mui grandes para volver ala unión. En las reflexiones generales que le hice $[. .$.$] me confesó que en verdad desde$ su ocupación, no solo había asoladose el pays, sino que también había retrogradado la moral de sus paysanos [...] Añadió que era él un labrador pacifico antes de la revolución, y que se le hizo entrar en ella en nombre del Rey, y que los acontecimientos posteriores lo conduxeron insensiblemente á un punto de que no pudo retroceder. Entonces le manifesté las disposiciones de V:E y la voluntad de la Nación para cicatrizar nuestras heridas, a estas aberturas se me declaró francamente que la calidad [...] de hermano del G. I. Artigas le era un impedimento para publicar sus sentimientos políticos; pero que no habiendo jamás recibido agravio del gobierno de la Metrópoli, no podía de ningún modo serle odioso; que sus costumbres é idioma eran vínculos demasiados dulces para romperlos de corazón [...] entonces me añadió, que en el caso de recabar su libertad por la protexión de V:E, no solo por gratitud, sino por una obligación emplearía todo su influxo tanto con su hermano como con toda la gente de la Campaña para indu- cirlos a que abrazen la Constitución (Frega, 2007, p. 478).

Al calor de la revolución liberal, el grupo encabezado por el marqués de Casa Florez y Mateo Magariños intentaba desvincular, a través de distintas estrategias, a la Provincia Oriental de la corte lusitana. Por ende, tanto la salida armada como la amnistía eran compatibles con sus objetivos de alcanzar la independencia definitiva del dominio lusitano. Mateo Magariños envió a su hijo una nota en la que indicaba que ya 37 jefes y oficiales de los patriotas de la Banda Oriental se habían presentado a jurar la constitución "con deseos de que los ocupen en la pacificación de tan fértiles provincias."

Ofrecían

reunir compañías de sus soldados esparramados, y el principal D.n Fernando Otorgues hasta quinientos hombres cree reunir, lo que no dificulto por la opiniòn qu goza en la campaña, lo mismo que d.n José Antonio Berdún, comandante General que era de Entre-rios, d.n Pablo Gadea, hazendado, Gefe del partido de Soriano y sus Subalternos, d.n Andres Artigas comandante General de los Pueblos de Miciones, y el hijo del nombrado D.n Jose Artigas, todos los cuales solo desean pasar á la banda oriental para ponerse en contacto con sus amigos y parciales, poder recolectar algunos caballos, y permanecer quietos hasta que se les avise si deben operar o no, manteniendose entretanto sin gravar al Estado, y observando la misma conducta con los dicidentes para no hacerse sospechosos. ${ }^{20}$

${ }^{20}$ Fondo Buenos Aires. Indiferente 1569. Río de Janeiro, 1 de mayo de 1821. Archivo General de Indias (AGI), España. 
Algo similar planteaba el marqués de Casa Florez al ministro de Ultramar, explicándole los auxilios brindados en dinero a españoles de la Banda Oriental que habían jurado la Constitución. Consideraba que, entre ellos, algunos podían ser útiles porque eran "cabezas de partido de las más principales y de mayor concepto”, tales como Otorgués, quien había operado como segundo al mando en relación con Artigas:

Este sujeto está enteramente decidido á favorecer y apoyar con todos los medios que pueda las fuerzas españolas qu vengan á ocupar á Montevideo y la Banda Oriental, y en prueba de su decidida resolución ha firmado un contrato con D.n Juan Almagro, Asesor que fuè del virreinato de Buenos Aires, y que posee cuantiosos bienes en la banda oriental, obligandose á administrarle sus haciendas, partiendo con el propietario los productos, y á acudir con caballos, carnes y víveres de toda clase à las primeras tropas Españolas que se presenten en aquellos países. Las miras políticas que me he propuesto en ganar á estos mencionados españoles, además de que una vez puestos en libertad y reducidos á la mayor miseria tal vez hubiera sido causa de que cometiesen algun desorden en esta corte, cuyas circunstancias son demasiado caóticas en el día de hoy para no tenerlas en consideración. ${ }^{21}$

Para los emigrados de Brasil, así como para los sectores afines que habían permanecido en la Provincia Oriental, la apelación a la fuerza era una alternativa para sostener "los derechos de la Nación y de todos los españoles que somos vecinos [sic]

${ }^{21}$ Fondo Buenos Aires. Indiferente 156. Río de Janeiro, 13 de mayo de 1821. AGI, España. de ella”. Culpaban a la revolución bonaerense de dar a Brasil "la ocasión de ocupar la Llabe [sic] del Rio de la Plata y de todo el Perú y nos ha quitado la fuente de nuestras riquezas y obstruido el canal del comercio". 22

Estos "españoles de ambos mundos" tenían claro que en la corte lusitana la situación de sus miembros era frágil y se mostraban también urgidos por sostener al marqués de Casa Florez, altamente expuesto a potenciales represalias. ${ }^{23}$ Pero ni Mateo Magariños ni sus aliados reducían sus miras y objetivos a la liberación política de la Banda Oriental. Uno y otros pensaban que podían - a partir de la desvinculación de la corte portuguesa- alcanzar el control del comercio regional y de ultramar a través de Montevideo, accediendo a un territorio mayor del que esa jurisdicción controlaba (Frega, 2009).

La inestabilidad política que había caracterizado al espacio litoraleño durante el año 1820 se profundizó en 1821 en la Provincia Oriental. Entre los meses de abril y octubre la correspondencia al interior del grupo y con las autoridades metropolitanas mostraba indicios del devenir del conflicto por ese espacio y la puja desatada.

Las dificultades a sortear no sólo implicaban a portugueses y bonaerenses sino también a otros actores, a otros grupos que habían permanecido en Montevideo. Si en el medio rural pervivían núcleos resistentes a la ocupación portuguesa, el sector hispano-criollo, cuya base de poder residía en el control del Cabildo montevi-

\footnotetext{
${ }^{22}$ Fondo Magariños. Caja 108, carpeta 3. Río de Janeiro, 26 de abril de 1821. AGN, Uruguay.

${ }^{23}$ Indiferente 1569. Carta de Mateo Magariños a su hijo Francisco. 26 de mayo de 1821. AGI, España.
} 
deano, se había aliado con el barón de la Laguna, Carlos Federico Lecor, ya que consideraba que podía obtener buenos réditos de la situación. Un momento culminante en esta pugna se produjo a fines de julio de 1821 cuando, bajo la presión portuguesa, el Congreso Extraordinario de Montevideo declaró la incorporación de la provincia al Reino Unido de Portugal, Brasil y el Algarbe con el nombre de Estado Cisplatino (Frega, 2009, p. 30). Si bien los grupos independentistas hablaban de la farsa que implicaba tal congreso, reconocían la existencia de sectores que avalaban este tipo de alianzas con los portugueses. Entre ellos estaban desempeñando un importante papel aquellos comerciantes que si bien eran "enemigos natos de toda revolución", habían "hallado un buen mercado en estas expediciones militares, porque han visto que los canales de sus lucros están unidos a los sucesos de la guerra". ${ }^{24}$

Era evidente que para todos los bandos - defensores de la metrópoli, independentistas, aliados a los lusitanos o partidarios de Buenos Aires- la guerra, más allá del desorden y el conflicto, operaba como una posibilidad de acumular tanto en la esfera mercantil como en la de propiedad de tierras y ganados. Pero, paralelamente, la compleja trama de vínculos en cuyo interior desplegaban sus estrategias los miembros de las elites de la Banda Oriental dejaba con frecuencia al descubierto la labilidad de las alianzas, las desconfianzas mutuas que impedían concretar un acuerdo definitivo y confiable entre los artiguistas y los españoles americanos.

\footnotetext{
${ }^{24}$ Fondo Buenos Aires. Indiferente 156. Carta. 19 de octubre de 1821. AGI, España.
}

En un escenario signado desde 1820 por la crisis de los dos proyectos de organización estatal de los pueblos del antiguo virreinato del Río de la Plata, el centralista y el de "los Pueblos Libres", tampoco el grupo de los españoles europeos encabezado entre otros por Mateo Magariños pudo concretar a la postre su plan "independentista" y de ensanchamiento de la jurisdicción montevideana (Frega, 2009, pp. 33-35).

Cuando en septiembre de 1821 las Cortes resolvieron no dar continuidad a los diputados suplentes por Ultramar, este último grupo perdió a uno de sus enlaces significativos, Francisco de Magariños. A ello se sumó el cambio de postura de la metrópoli con respecto a los territorios del Río de la Plata, ya que las autoridades decidieron volcar todos sus esfuerzos en la "conservación de aquellos territorios que aún no habían logrado su independencia”. El virreinato del Perú se transformó a partir de entonces en el foco de atención. Ello impulsó a algunos miembros del grupo de Río de Janeiro a emigrar hacia aquellas tierras, entre ellos a Mateo Magariños. Según algunos biógrafos, este arribó en setiembre de 1824 al puerto de Arica para ocupar la silla de la Real Audiencia de Chuquisaca, pero dado el triunfo de las armas revolucionarias, cayó prisionero. Cuando lo liberaron se alejó de la política, reabriendo su despacho de abogado en Arequipa, donde permanecería hasta su muerte (Mora, 1919, pp. 454-455).

Francisco de Magariños debería enfrentar, desde Londres, el acto final: la crisis del proyecto liberal en 1823 y el retorno del absolutismo de la mano de la Santa Alianza. Todavía en agosto de ese año sus contactos con uno de los miembros del 
último gabinete liberal del Trienio, Juan Antonio Yandiola -con quien compartió no sólo el espacio de las Cortes sino posiblemente preocupaciones afines sobre las experiencias americanas-, mostraban a un Magariños deseoso y confiado en el triunfo de lo que consideraba una "causa" compartida. ${ }^{25}$ En lugar del triunfo les esperaba una derrota que debió acelerar su transmutación de español americano a americano y, particularmente, su identificación excluyente con la causa oriental. Como otros españoles americanos, tuvo que internalizar duramente que el camino de unidad con España estaba agotado.

A su vez, los acontecimientos rioplatenses debieron estimular las condiciones del retorno. Luego de la "Cruzada Libertadora" dirigida por Juan Antonio Lavalleja (1825), la subsiguiente declaración de independencia del reino de Portugal y del emperador de Brasil, así como la integración transitoria de la Provincia Oriental a las restantes del Río de la Plata, se produjo el regreso a Montevideo de Francisco y sus hermanos militares, no así el de su padre. Restarían todavía varios años de enfrentamientos para llegar a la denominada "unanimidad patricia", que concretaría en 1830 el pacto constitucional, abriendo una tregua a las confrontaciones (Frega, 2009, pp. 44-45).

El "hombre de dos mundos" que dio inicialmente muestras evidentes de su validación de la monarquía, había madurado en el transcurso de la experiencia liberal europea y concluiría su carrera polí-

\footnotetext{
${ }^{25}$ Fondo Magariños. Caja 107, carpeta 14. AGN, Uruguay. Con Juan Antonio Yandiola también es posible que lo unieran tradiciones familiares comunes al ser ambos miembros de tramas mercantiles relevantes en sus respectivos espacios.
}

tica, años más tarde, defendiendo libertades y derechos en el marco de una república independiente cuya representación asumió.

\section{El sueño liberal desde la mirada de un español americano}

¿Cómo operó en su corta trayectoria como diputado este montevideano tan fuertemente involucrado en las disputas del espacio rioplatense? Si evidentemente su lógica de representación estuvo ligada a las expectativas y demandas de esos "representados" que en sentido genérico se autodenominaban "españoles americanos", primaron en sus posicionamientos aquellas perspectivas e "intereses particulares" vinculados a la fracción de la elite montevideana exilada en la Corte del Brasil, la cual estaba dirimiendo su lugar en el orden poscolonial.

Su accionar al interior de las Cortes tuvo estrategias bien definidas. En primer lugar, cuando entre 1820 y 1821 , aspirando aun a que la metrópoli diera una respuesta armada a los movimientos rioplatenses, se integró como miembro de una comisión especial y propuso extender el Reglamento de las Milicias Nacionales a ultramar. Como ciudadano y "hombre libre" reclamó esta medida por cuanto las colonias ultramarinas pertenecían "a la gran Nación y por lo tanto tienen derecho a recibir auxilios de defensa que se le conceden a todo español, a todo hombre libre". ${ }^{26}$

Los argumentos de los que se valió ante las Cortes recuperaron una y otra vez

${ }^{26}$ Diarios de Sesiones del Congreso. 23 de agosto de 1820, pp. 627-628. ACD 
la dura y compleja situación de la América del Sur, mostrando su desconfianza sobre el apoyo popular de los movimientos revolucionarios: "lo que se llama pueblo jamás influye ni resuelve sobre ningún punto". ${ }^{27}$

Desde su perspectiva, una intervención armada no debía considerarse aisladamente sino inscrita en una visión geopolítica y económica del imperio. Sólo comprendiendo el problema en toda su complejidad se preservaría a la región "de las piraterías de los corsarios de las muchas propiedades de españoles americanos y españoles europeos que se transportan a América y que de ella extraen para la Península". El control militar del área, al alejar toda anarquía, evitaría concomitantemente "que los extranjeros se lleven los frutos y el dinero que debía recibir la Nación de aquellas ricas y fértiles provincias". ${ }^{28}$

Nunca perdió de vista ese eje vital de articulación entre la metrópoli y América que configuraba el tráfico mercantil. Su experiencia personal y grupal lo estimulaba a derribar las barreras que lo entorpecieran y que las otras potencias aprovechaban tan eficazmente. Por ende, propuso hacer extensivas las medidas de liberalización otorgadas a zonas y/o a los europeos españoles residentes en la península hacia todos los espacios y comerciantes españoles americanos. ${ }^{29}$

Su compromiso con los criterios de igualdad y equidad entre españoles euro-

${ }^{27}$ Fondo Buenos Aires. Indiferente 156, fs. 340343, 19 de octubre de 1821. AGI, España.

${ }^{28}$ Diarios de Sesiones del Congreso. 30 de marzo de 1821, pp. 771-773. ACD.

${ }^{29}$ Diarios de Sesiones del Congreso. 9 de agosto de 1820 , p. 450; 15 de agosto de 1820, p. 521; 19 de agosto de 1820, p. 573; 28 de agosto de 1820, p. 69. ACD. peos y españoles americanos lo condujo también a discutir la integración de religiosos al Consejo de Estado, sugiriendo la necesidad de incorporar a dos americanos sobre los cuatro posibles. ${ }^{30}$ Paralelamente, y no escatimando esfuerzos para expandir la formación de los grupos dirigentes rioplatenses, estimuló la creación de las universidades de segunda enseñanza en Montevideo y Córdoba, y en Buenos Aires la destinada a los estudios para la tercera enseñanza. ${ }^{31}$

El involucramiento con la "causa" americana no corrió en paralelas con el relativo a los grandes debates del trienio. ${ }^{32}$ En esta dirección sus intervenciones fueron escasas o nulas. Tal vez una de las más destacables fue la proposición en defensa de la libertad individual y de la libertad de imprenta, dos derechos fuertes en la carta gaditana que habían marcado su trayectoria individual y por los que había apelado en distintos momentos. Con una perspectiva "garantista”, el diputado sugirió la creación de "una Junta de protección, que haciendo la parte del acusado, saliera a la defensa de cualquier papel denunciado que merezca su protección" a fin de neutralizar

${ }^{30}$ Diarios de Sesiones del Congreso. 21 de julio de 1820 , p. 23. ACD; Fondo Buenos Aires. Indiferente 1569, 26 de mayo de 1821. AGI, España. En una carta del 3 de junio de 1820 dirigida a Francisco, Mateo le propone que tramite un obispado poniendo al frente a Chorroarín o a Larrañaga quienes, si bien habían adoptado el partido de la revolución, se encontraban desengañados.

${ }^{31}$ Diarios de Sesiones del Congreso. 21 de octubre de 1820, p. 1833. ACD.

${ }^{32}$ Para este tema existe una extensa bibliografía contemporánea entre la que se destacan los trabajos de Varela (1983); Breña (2006); Frasquet (2008); Chust (1999). 
los abusos. ${ }^{33}$ Su perspectiva en torno a la libertad de opinión se articulaba coherentemente con su planteo de aceptación del disenso.

El diputado americano que a lo largo de su trayectoria fue internalizando y resignificando las nuevas lógicas de representación, sólo en algunos momentos pudo convertirse en intérprete de intereses generales, ya que con mayor frecuencia operó como portavoz de intereses "particulares".

Cuando llegamos al final del relato, sobre el conjunto de interrogantes iniciales prima aquel relativo a lo que estuvo en juego en todo este proceso, como lo marcaba el epígrafe.

Más allá de los indicios que nos condujeron a recuperar unas vidas, sus incertidumbres, sus miradas del mundo o sus desconciertos frente a los acontecimientos, volvemos a preguntarnos sobre los aportes que el género biográfico puede generar para una mejor comprensión de la cultura política decimonónica.

Este último registro es ya de por sí una referencia altamente valorable: vivenciar a los actores individuales y colectivos, percibirlos enfrentando, con sus dilemas y circunstancias, los asuntos del poder. Al mismo tiempo pensamos que dicho género nos ha permitido observarlos en una multiplicidad de ámbitos simultáneos al interior de configuraciones sociales complejas. Las formas y dinámicas que las mismas adoptaron fueron diseñando una densa geografía de las relaciones de poder en una coyuntura de desestructuración del proyecto imperial hispánico y de modificación del estatuto de los reinos

${ }^{33}$ Diarios de Sesiones del Congreso.16 de octubre de 1820, p. 1075. ACD. americanos. Si la usurpación del trono y la posterior sanción de la constitución gaditana impulsaron la desarticulación de los marcos institucionales precedentes, modelando acciones y relaciones políticas que tuvieron consecuencias directas no sólo sobre el devenir peninsular sino sobre todo el antiguo espacio imperial, obligaron al mismo tiempo a redefinir los compromisos preexistentes con la autoridad suprema y a buscar estrategias para legitimar los nuevos poderes. Mientras algunos espacios iniciaban su recorrido orientándose a consolidar su autonomía, otros realimentaban en una dinámica conflictiva sus antiguos vínculos. Ello dio una cierta especificidad a las formas de representación que emergieron para asegurar tanto la legitimidad de los nuevos poderes como la renovada articulación entre la monarquía constitucional y los ciudadanos españoles americanos que en esas coyunturas se asumieron como sujetos de representación y avalaron las formas electorales de la que emergieron sus representantes.

En segundo lugar, creemos que ilumina una dimensión del proceso independentista rioplatense que había quedado, si no oculto, por lo menos velado ante los enfrentamientos que opusieron al proyecto centralista encarnado por Buenos Aires y el de los Pueblos Libres tras la figura de José Gervasio Artigas. Esta dimensión se vincula con la presencia y el accionar de esas fracciones de españoles americanos que configuraban un núcleo significativo de la elite montevideana. Muchos de sus miembros habían formado parte de la fase expansiva de la burocracia borbónica que diera luz -hacia finales del siglo XVIII- al virreinato del Río de la Plata, y habían tenido un asentamiento inicial en Buenos Aires. A estos actores se habían sumado 
comerciantes y militares que operaron en ese proceso de crecimiento de una economía metropolitana y que no sólo pretendían consolidar su expansión sino convertirla en una verdadera cuña frente a ingleses y portugueses. La transferencia hacia el espacio montevideano de parte de esa burocracia que articuló sus tareas con los negocios - usufructuando tanto las tramas de vínculos entre las colonias y la metrópoli como las ventajas que ofrecían la oferta y demanda regionales- le permitió a sus integrantes no sólo un creciente nivel de injerencia en la disputa por el poder político, sino por la hegemonía regional en un sentido más amplio. En ese contexto tuvo un papel nodal la guerra como problema pero también como oportunidad política y económica. El devenir de los conflictos permitió percibir con claridad las tensiones y el grado de inestabilidad al que estuvieron sometidos los actores, las incertidumbres que los impulsaron en lapsos breves a modificar sus posiciones políticas y a buscar alternativas, a veces sin un objetivo prefijado entre las orientaciones monárquicas y las liberales.

Paralelamente emergieron indicios interesantes sobre las lógicas de representación de esos actores y la recurrente asimilación de la soberanía a la defensa de los intereses propios de una ciudad y su hinterland. Pero también sus mutaciones y dilemas entre la búsqueda de un compromiso con una autoridad suprema y la concreción de una organización política de dimensiones provinciales.

Finalmente, y en este intento de primer balance, creemos que es importante recuperar la pregunta sobre la capacidad de acción de este individuo llamado Francisco de Borja Magariños y Cerrato así como de aquellos otros que, como él, se hallaban inmersos en complejas tramas de relaciones familiares, de amistad, de negocios y de poder frente a los enormes desafíos que suponían la crisis del proyecto imperial y la emergencia de nuevos estados. Justamente el caso da cuenta de los condicionamientos pero también de las potencialidades de incidencia que tuvieron esos actores colectivos, de cómo operaron al interior de reglas de juego que los excedían pero también de sus "capacidades" para redefinir, readaptar, resignificar sus contenidos. Paralelamente nos ratifica en la necesidad de nunca escindir las tramas específicamente políticas de las otras dimensiones culturales en unas sociedades que, como las decimonónicas, están haciendo su tránsito desde el antiguo régimen hacia las lógicas liberales. El recorrido biográfico realizado convalida lo que nos advertía la voz de Isabel Burdiel al principio de nuestra exposición, ya que sólo es posible lograr una mejor comprensión de la cultura y de las prácticas políticas decimonónicas al trascender la separación formal que la teoría liberal pretende establecer entre lo privado y lo público.

\section{LISTA DE REFERENCIAS}

-Archivo Artigas (t. v, pp. 36-46) (1963). Montevideo: Impresores A. Monteverde y Compañía S. A.

-Betancur, A. (1996). Vida privada de los comerciantes en el Montevideo colonial. En J. P. Barrán, G. Caetano, T. Porzecanski, Entre la bonra y el desorden 1780-1870. Historias de la vida privada en el Uruguay (t. 1, pp. 96-119). Montevideo: Taurus.

-Betancur, A. (1999). El puerto colonial de Montevideo. Los años de la crisis (1807-1814) (t. II).

\section{()ㅜ(1) $(9$}


Montevideo: FHCE/CSIC-Universidad de la República.

-Betancur, A. (2011). La familia en el Río de la Plata a fines del periodo Hispánico. Historias de la sociedad montevideana. Montevideo: Planeta.

-Breña, R. (2006). El primer liberalismo español y los procesos de emancipación de América, 18081824. México: El Colegio de México.

-Burdiel, I. (2004). Isabel II. No se puede reinar inocentemente. Madrid: Espasa Calpe.

-Caula, E. (2002). Negocios y estrategias de una red mercantil a comienzo del siglo XIX. En Cuadernos de Trabajo. Buenos Aires: Universidad Argentina de la Empresa.

-Caula, E. (octubre 2009). La lealtad al rey de los "europeos españoles" emigrados a Río de Janeiro y los planes de reconquista de los territorios de ultramar [mimeo]. XII Jornadas InterEscuelas-Departamentos de Historia, Bariloche.

-Chiaramonte, J. C. (2000). Fundamentos iusnaturalistas de los movimientos de independencia. Boletín del Instituto de Historia Argentina y Americana Dr. E. Ravignani, 22, 33-71.

-Chust, M. (1999). La cuestión nacional americana en las Cortes de Cádiz (1810-1814). Valencia: UNED/Fundación Instituto Historia Social/UNAM.

-Di Stefano, R. (2002). La revolución de las almas: religión y política en el Río de la Plata insurrecto (1806-1830). En N. Calvo, R. Di Stefano, K. Gallo (coords.), Los curas de la Revolución (pp. 13-27). Buenos Aires: Emecé.

-Dosse, F. (2007). La apuesta biográfica. Escribir una vida. Valencia: Universidad de Valencia.

-Elliott, J. (2006). Imperios del mundo atlántico: España y Gran Bretaña en América, 14921830. Madrid: Taurus.

-Frasquet, I. (2008). Ciudadanos: ya tenéis Cortes. La convocatoria de 1820. En J. E. Rodríguez O. (coord.), Las nuevas naciones. España y México 1800-1850 (pp. 145-168). Madrid: Fundación MAPFre.
-Frega, A. (2007). Pueblos y soberanía en la revolución artiguista. Montevideo: Ediciones de la Banda Oriental.

-Frega, A. (2009). Alianzas y proyectos independentistas en los inicios del "Estado Cisplatino". En A. Frega (coord.), Historia regional e independencia del Uruguay (pp. 19-63). Montevideo: Banda Oriental.

-Goldaracena, R. (1978). El libro de los Linajes. Montevideo: Arca.

-Guerra, F. X. (1994). La desintegración de la monarquía hispánica: revolución e independencia. En A. Annino, L. Castro Leiva, F. X. Guerra, De los imperios a las naciones: Iberoamérica (pp. 195-228). Zaragoza: IberCaja.

-Levi, G. (1989). Les usages de la biographie. Annales ESC, 6, novembre-décembre, 1325-1336.

-Loriga, S. (1996). La biographie comme problème. En J. Revel, Jeux d'échelles. La microanalyse à l'expérience (pp. 209-231). París: Gallimard et Le Seuil.

-María, I. de (1879). Rasgos biográficos de bombres notables de la República Oriental del Uruguay (tt. I-II). Montevideo.

-Mariluz Urquijo, J. M. (1958). Los proyectos españoles para reconquistar el Río de la Plata (1820-1833). Buenos Aires: Editorial Perrot.

-Mora Magariños, R. (1919). Los primeros Magariños venidos al Río de la Plata. Revista Histórica, IX(26), 426-496. Publicado por el Archivo y Museo Histórico Nacional, Montevideo.

-Pereira Das Neves, G. (1994). Del imperio luso-brasileño al Imperio del Brasil (1789-1822). En A. Annino, L. Castro Leiva, Guerra, F. X., De los imperios a las naciones: Iberoamérica (pp. 169-194). Zaragoza: IberCaja.

-Portillo Valdés, J. M. (2006). Crisis atlántica. Autonomía e independencia en la crisis de la monarquía bispana. Madrid: Marcial Pons.

-Revel, J. (2005). La biografía como problema historiográfico. En J. Revel, Un momento 
historiográfico. Trece ensayos de historia social (pp. 217-228). Buenos Aires: Manantial.

-Rodríguez O., J. E. (ed.) (2005). Revolución, independencia y las nuevas naciones de América. Madrid: MAPFRE Tavera.

-Sierra, M. (2010). Parlamentos y representación: puentes biográficos entre España y América (1808-1898). En Avances del Cesor, año VII(7), 95-114. ISHIR-CESOR-CONICET, Rosario.

-Varela Suanzes Carpegña, J. (1983). La teoría del Estado en los orígenes del constitucionalismo hispánico (Las Cortes de Cádiz). Madrid: Centro de Estudios Constitucionales.

\section{OTRAS FUENTES}

Archivos

ACD Archivo de Cortes de Diputados.

AGN Archivo General de la Nación, Uruguay. AGI Archivo General de Indias. 